\title{
Karakterisasi Internal Transcribed Spacer (ITS) rDNA Nematoda Pucuk Putih (Aphelenchoides besseyi Christie)
}

\section{(Characterization of The Internal Transcribed Spacer(ITS) rDNA of White Tip Nematode (Aphelenchoides besseyi Christie))}

\author{
Ade Indra Maulana Sembiring ${ }^{1}$, Fitrianingrum Kurniawati ${ }^{1 *}$, dan Supramana ${ }^{1}$ \\ ${ }^{1}$ Departemen Proteksi Tanaman, Fakultas Pertanian, Institut Pertanian Bogor \\ J1. Kamper, Kampus IPB Dramaga, Bogor, Indonesia, 16680 \\ *Email korespondensi: fitrianingrumk@gmail.com
}

Diterima 21 Maret 2019/Disetujui 10 Mei 2019

\begin{abstract}
Aphelenchoides besseyi is an important plant parasitic nematode on rice and causes yield loss up to 54\%. Information regarding A. besseyi in Indonesia is limited. The objective of this research is to identify A. besseyi based on the ITS region and to analyze the nucleotide sequences of the ITS region. The nematode A. besseyi extracted from $6 \mathrm{~g}$ seed from seven rice seed cultivars there are Ciherang, Gondo Roso, Hibrida Prima, Inpari Sidenuk, Pertiwi, Pandan Wangi, and Sintanur. Nematode extraction was conducted by the modified Baermann Funnel method. Molecular identification with PCR included extraction, amplification, and electrophoresis of DNA, and analysis of nucleotide sequences. Sequencing analysis was carried out with BLAST, ClustalW, Boedit v 7.0.5.3, and MEGA v.7.0. DNA amplification was performed using a specific forward primer (5'ACA ATC GAG TTG GGA GTG-3') and reverse primer (5'-GGT CAG TGT CAT CAA TCG-3'). The DNA amplification resulted an $750 \mathrm{bp}$ fragment of $A$. besseyi. The results of nucleotide alignment obtained 555 nucleotides. The homology of nucleotides of Indonesian A. besseyi extracted from Hibrida Prima and Pandan Wangi showed 100\% with China and Russia isolates, while isolate of Gondo Roso showed $100 \%$ similarity with India isolate. The homology of Indonesian isolates with outgroup isolate of A. primadentus from Iran was $74.4 \%$. Differences in nucleotide sequencing are located in positions 216 , 376, and 448. These results showed that A. besseyi isolates from Indonesia are closely related to isolates from China, Russia and India.
\end{abstract}

Keywords: alignment analysis, homology, phylogenetic analysis

\begin{abstract}
ABSTRAK
Aphelenchoides besseyi merupakan nematoda parasit tumbuhan penting pada padi dan dapat menyebabkan kehilangan hasil hingga 54\%. Informasi mengenai nematoda A. besseyi di Indonesia masih sangat terbatas. Penelitian ini bertujuan mengidentifikasi A. besseyi berdasarkan daerah ITS dan menganalisis runutan nukleotida dari daerah ITS. Nematoda A. besseyi diekstraksi dari $6 \mathrm{~g}$ benih dari tujuh varietas padi, yaitu Ciherang, Gondo Roso, Hibrida Prima, Inpari Sidenuk, Pertiwi, Pandan Wangi, dan Sintanur. Ekstraksi nematoda dilakukan dengan metode Corong Baermann yang telah dimodifikasi. Identifikasi molekuler dengan PCR mengamplifikasi wilayah ITS menggunakan pasangan primer spesifik forward (5'-ACA ATC GAG TTG GGA GTG-3') dan reverse (5'-GGT CAG TGT CAT CAA TCG-3'). Hasil amplifikasi DNA A. besseyi diperoleh fragmen berukuran sekitar $\pm 750 \mathrm{bp}$. Hasil analisis penyejajaran diperoleh 555 nukleotida. Isolat A. besseyi asal Indonesia varietas Inpari Sidenuk, Ciherang, Hibrida Prima, dan Pandan Wangi menunjukkan homologi nukleotida $100 \%$ dengan isolat asal Cina dan Rusia, serta varietas Sintanur, Pertiwi, dan Gondo Roso memiliki homologi $100 \%$ dengan isolat asal India. Perbandingan homologi isolat asal Indonesia dengan outgroup isolat A. primadentus asal Iran menunjukkan kemiripan nukleotida 74.4\%. Perbedaan runutan nukleotida antar isolat terletak pada posisi 216, 376, dan 448. Hal tersebut menunjukkan isolat asal Indonesia memiliki tingkat kesamaan yang tinggi dan berkerabat sangat dekat dengan isolat asal Cina, Rusia, dan India.
\end{abstract}

Kata kunci: analisis filogenetika, analisis penyejajaran, homologi

\section{PENDAHULUAN}

Aphelenchoides besseyi mwrupakan nematoda penting pada komoditas padi. Infeksi dari A.besseyi menyebabkan penyakit pucuk putih (white tip). Nematoda ini menginfeksi bagian tajuk tanaman sehingga sering disebut sebagai foliar nematode. Nematoda $A$. besseyi juga merupakan nematoda terbawa benih yang dapat bertahan 
pada benih dalam kondisi anhidrobiosis selama penyimpanan di gudang (Kurniawati \& Supramana, 2016). EPPO (2005) melaporkan penyebaran nematoda ini sudah mencapai seluruh negara Eropa, Afrika, Amerika Serikat dan beberapa negara di Asia termasuk Indonesia. Namun, di Indonesia sendiri penyebaran $A$. besseyi masih terbatas di beberapa wilayah saja, yakni Sumatera, Jawa dan Kalimantan Selatan, sehingga status dari patogen ini merupakan sebelumnya organisme pengganggu tumbuhan karantina OPTK A2 menurut Kementan (2015) menjadi OPT penting (Kementan, 2018).

Kurniawati \& Supramana (2016), melaporkan keberadaan nematoda $A$. besseyi di beberapa varietas padi di Bogor yang merupakan varietas benih paling banyak digunakan oleh petani di Indonesia. Penelitian tersebut juga telah melakukan identifikasi secara morfologi. Namun, dibutuhkan ketelitian khusus untuk mengidentifikasi secara morfologi. Identifikasi secara molekuler atau PCR sangat

\section{BAHAN DAN METODE}

\section{Ekstraksi Nematoda}

Nematoda A. besseyi diekstraksi dari tujuh varietas padi, yaitu Ciherang, Gondo Roso, Hibrida Prima, Inpari Sidenuk, Pertiwi, Pandan Wangi dan Sintanur. Benih tersebut didapatkan dari kios pertanian di Sumatera Utara dan Jawa Tengah. Sebanyak $6 \mathrm{~g}$ benih diambil dengan 3 ulangan mengacu kepada metode Remeeus \& Pelazza (2014) yang dimodifikasi. Benih diekstraksi menggunakan metode Corong Baermann yang telah di modifikasi, bagian hilum benih dipotong, kemudian diletakkan di atas gelas yang pada bagian dasarnya terdapat saringan nilon. Benih selanjutnya diletakkan pada gelas penampung yang berisi air. Dasar saringan menyentuh permukaan air sampai benih terendam air dan diinkubasi selama 24 jam pada ruangan gelap pada suhu ruang. Nematoda yang tertampung di dalam air kemudian disaring menggunakan saringan 100 mesh dan 500 mesh dan hasilnya dimasukkan ke dalam tabung berukuran $1.5 \mathrm{ml}$.

\section{Identifikasi Berdasarkan Polymerase Chain Reaction (PCR) rDNA}

Ekstraksi DNA dilakukan menggunakan metode Cetyl Trimethyl Ammonium Bromide (CTAB) Doyle \& Doyle (1990) yang telah dimodifikasi. Bufer ekstraksi sebanyak $150 \mathrm{ml}$ disiapkan terlebih dahulu. Sebanyak 30-35 ekor nematoda hasil ekstraksi selanjutnya dipancing dan dimasukkan ke dalam tabung eppendorf $1.5 \mathrm{ml}$. Bufer ekstraksi $150 \mu \mathrm{l}$ dan $1 \% \beta$-mercaptoetanol ditambahkan ke dalam tabung mikro, kemudian digerus menggunakan micropestle, lalu diinkubasi pada suhu $60-65{ }^{\circ} \mathrm{C}$ selama 2 jam (tabung dibolak-balik setiap 10 menit untuk membantu proses lisis).

Hasil inkubasi didiamkan pada suhu ruang selama 35 menit. Siapan ditambahkan dengan campuran kloroform:isoamil alkohol (C:I) 24:1 sebanyak $150 \mu \mathrm{l}$, dicampurkan hingga homogen dengan menggunakan vortex dibutuhkan untuk meningkatkan keakuratan dari hasil identifikasi morfologi dan analisis perunutan diperlukan untuk memperkuat hasil PCR dan mengetahui runutan nukleotida maupun asam amino suatu organisme, serta dapat mengetahui asal usul organisme tersebut.

ITS adalah suatu urutan RNA dari proses transkripsi utama yang berada antar prekusor ribosomal subunit dan dihilangkan pada proses splicing ketika RNA precursor tanda molekul yang struktural diproses ke dalam suatu ribosom. Organisme eukariotik mempunyai dua daerah ITS; ITS-1 terletak di antara $18 \mathrm{~S}$ gen dan $5,8 \mathrm{~S}$ gen, dan ITS-2 terletak di antara $5,8 \mathrm{~S}$ dan $28 \mathrm{~S}$ gen. Ketiga gen ribosom tersebut mempunyai tingkat konservasi yang sangat tinggi (Gomes et al., 2002; O'Brien et al., 2005). Penelitian ini bertujuan mengidentifikasi Aphelenchoides besseyi asal tujuh varietas padi melalui perunutan nukleotida Internal Trascribed Spacer (ITS) dan mengetahui kedekatan genetiknya dengan negara lain.

selama 3 menit. Suspensi disentrifugasi pada kecepatan 11 $000 \mathrm{rpm}$ selama 20 menit. Supernatan lapisan atas diambil sebanyak $80 \mu \mathrm{l}$ dan dimasukkan ke dalam tabung mikro 1.5 $\mathrm{ml}$ baru dengan label yang sama. Supernatan ditambahkan dengan $1 / 10$ volume sodium asetat (CH3COOK $3 \mathrm{M}$; $\mathrm{pH} 5.2$ ) dan $2 / 3$ volume isopropanol dari total volume. Selanjutnya diinkubasi pada suhu $-20{ }^{\circ} \mathrm{C}$ selama overnight. Tabung kemudian disentrifugasi pada kecepatan $12000 \mathrm{rpm}$ selama 15 menit. Supernatan dibuang, kemudian ditambahkan 150 $\mu 1$ etanol $80 \%$ dan disentrifugasi kembali pada kecepatan 12 $000 \mathrm{rpm}$ selama 15 menit. Supernatan dibuang dan pelet dikeringkan selama 1-2 jam. Pelet kemudian diresuspensi dengan $30 \mu \mathrm{l}$ bufer Tris-EDTA pH 8 dan disimpan pada suhu $-20{ }^{\circ} \mathrm{C}$ sampai digunakan sebagai templat dalam PCR.

Amplifikasi DNA dilakukan dengan menggunkan pasangan primer spesifik ITS $A$. besseyi dengan runutan forward (5'-ACA ATC GAG TTG GGA GTG-3') dan runutan reverse (5'-GGT CAG TGT CAT CAA TCG-3') (Kurniawati, komunikasi pribadi 23 April 2018). Reaksi amplifikasi terdiri atas beberapa reaksi, predenaturasi dengan suhu $94{ }^{\circ} \mathrm{C}$ selama 4 menit dan denaturasi pada suhu $94{ }^{\circ} \mathrm{C}$ selama 1 menit, annealing (penempelan primer) pada suhu $55^{\circ} \mathrm{C}$ selama 1 menit, dan elongasi pada suhu $72{ }^{\circ} \mathrm{C}$ selama 2 menit, siklus ini berlangsung sebanyak 30 kali dengan terakhir pasca elongasi pada suhu $72{ }^{\circ} \mathrm{C}$ selama 10 menit (Kurniawati, komunikasi pribadi 23 April 2018). DNA nematoda hasil amplifikasi dielektroforesis pada tegangan $50 \mathrm{~V}$ selama 50 menit. Hasil elektroforesis divisualisasikan dengan UV transilluminator dan diambil foto dengan kamera.

\section{Analisis Perunutan Nukleotida}

Hasil PCR dikirim ke PT. Genetika Science Indonesia untuk disekuensing. Hasil sekuensing yang didapatkan dianalisis menggunakan program CLC Sequence Viewer v 8.0. Hasil perunutan nukleotida yang diperoleh kemudian dikonfirmasi ke GenBank dengan program Basic Local Alignment Search Tool (BLAST) yang tersedia pada National Center for Biotechnology Information (NCBI, 2014). Kemudian nukleotida yang telah dikonfirmasi 
disejajarkan dengan menggunakan penyejajaran berganda ClustaIW pada program Bioedit Sequence Alignment Editor v 7.2.6 (Hall, 1999).

\section{Analisis Filogenetika A. Besseyi}

Analisis filogenetika dilakukan menggunakan pendekatan 'Maximum Likelihood' dengan Bootstrap 1000× dengan perangkat lunak Molecular Evolutionary Genetic Analysis Software versi 7 (MEGA 7).

\section{HASIL DAN PEMBAHASAN}

\section{Morfologi Nematoda Aphelenchoides besseyi}

Karakter morfologi dari nematoda $A$. besseyi memiliki tubuh berbentuk silinder memanjang (vermiform), anulasi halus, dan bibir set off (Gambar 1 a,b,d). Nematoda betina memiliki ukuran tubuh lebih panjang dibandingkan dengan jantan. Nematoda betina akan membentuk posisi lurus atau sedikit melengkung pada posisi istirahat. Nematoda ini memiliki stilet berbentuk seperti tombak dengan basal knob yang kecil (Gambar 1c ) dan terdapat median bulbus yang berukuran besar serta berbentuk oval
(Gambar 1d). Tubuh nematoda jantan pada bagian posterior melengkung hingga $180^{\circ}$ dengan spikula yang seperti duri (Thorne shaped spicule) dengan ekor berbentuk conoid dengan 2-4 mucro (tonjolan) (Gambar 1e). Nematoda betina memiliki vulva dengan tipe didelfik yang terletak pada 60 $75 \%$ panjang tubuhnya (Gambar 1f) (Kurniawati \& Supramana, 2016).

\section{ITS rDNA $A$. besseyi}

Menurut Vrain \& McNamara (1994) bahwa, setiap spesies, populasi, atau komunitas ekologi nematoda dapat dianalisis dengan menggunakan pendekatan molekuler berdasarkan wilayah rDNA ITS. Isolat yang berasal dari tujuh varietas padi yaitu, Ciherang, Gondo Roso, Hibrida Prima, Inpari Sidenuk, Pertiwi, Pandan Wangi dan Sintanur menunjukkan hasil positif dengan pita DNA yang sejajar. Identifikasi molekuler menggunakan PCR dengan primer ITS sebagai target amplifikasi dapat digunakan sebagai metode identifikasi nematoda $A$. besseyi yang akurat dan efisien. Hasil amplifikasi dinyatakan positif mengandung $A$. besseyi (Gambar 2).

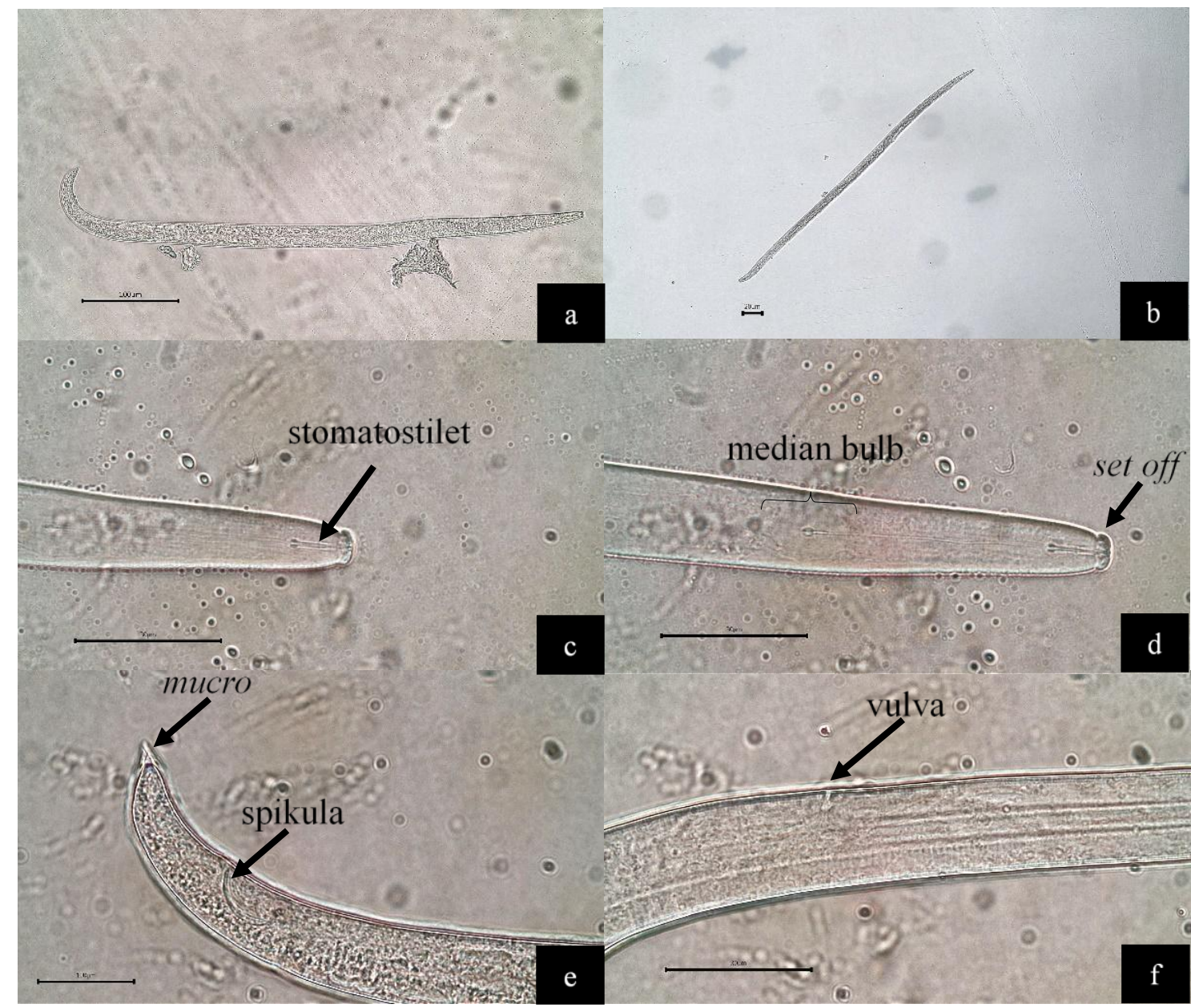

Gambar 1. Morfologi nematoda A. besseyi dari tujuh varietas benih padi asal Indonesia; (a) nemtoda jantan; (b) nematoda betina; (b) anterior nematoda; (d) metakorpus; (e) spikula; (f) vulva 


\section{Runutan Nukleotida Aphelenchoides besseyi}

Hasil perunutan ITS rDNA $A$. besseyi isolat Indonesia dari varietas Sintanur, Pertiwi, Inpari Sidenuk, Ciherang, Gondo Roso, Hibrida Prima, dan Pandan Wangi berhasil dirunut dengan panjang sekitar 555 nukleotida. Analisis kesejajaran menunjukkan bahwa ITS rDNA dari tujuh varietas asal Indonesia memiliki homologi identik dengan negara lain, yakni India, Cina, Rusia, dan Taiwan. Namun terdapat perbedaan nukleotida asal India dan varietas Sintanur, Pertiwi, dan Gondo Roso yang terletak pada posisi nukleotida ke 448 (Gambar 3). Serta terdapat perbedaan nukleotida pada isolat Taiwan di posisi ke 216, 376, dan 448 terhadap isolat Inpari Sidenuk, Ciherang, Hibrida Prima, dan Pandan Wangi.

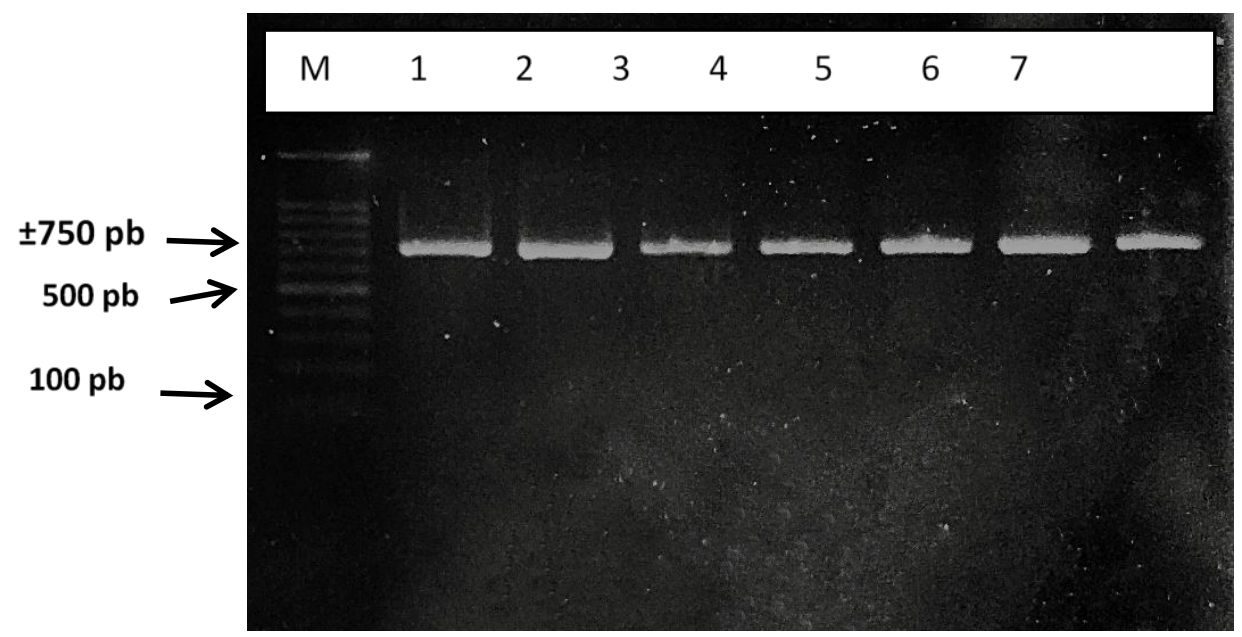

Gambar 2. Hasil amplifikasi daerah ITS rDNA A. besseyi (M) Marker 100pb (ThermoScientific USA); (1) Ciherang; (2) Gondo Roso; (3) Hibrida Prima; (4) Inpari Sidenuk; (5) Pandan Wangi; (6) Pertiwi; (7) Sintanur

A.b_Sintanur
A.b_Pertiwi
A.b_Inpari Sidenuk
A.b_Ciherang
A.b_Gondo Roso
A.b_Hibrida Prima
A.b_Pandan Wangi
A.b_India
A.b_Cina
A.b_Rusia
A.b_Taiwan
A.P_Ira
Clustal Co

A.b Sintanur

A.b Pertiwi

A.b-Inpari Sidenuk

A.b_Ciherang

A.b Gondo Roso

A.b-Hibrida Prima

A.b_Pandan Wangi

A.b-India

A.b Cina

A.b Rusia

A.b_Taiwan

A.P-Iran

Clustal Co

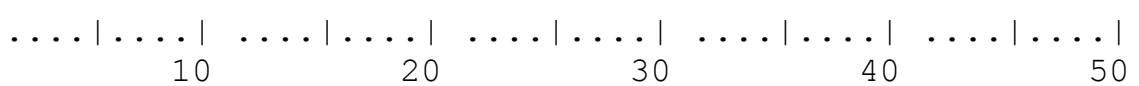

GTGCCGGGTG CGGATATTCG ACGTCGTCGT GAAGCACTCG GTATTTCCCG

GTGCCGGGTG CGGATATTCG ACGTCGTCGT GAAGCACTCG GTATTTCCCG

GTGCCGgGtg CGgAtATTCG ACGTCGTCGT GAAGCACTCG GTATTTCCCG

GTGCCGGgTG CGgAtATTCG ACGTCGTCGT GAAGCACTCG GTATTTCCCG

GTGCCGGGTG CGgAtATTCG ACGTCGTCGT GAAGCACTCG GTATTTCCCG

GTGCCGGGTG CGGATATTCG ACGTCGTCGT GAAGCACTCG GTATTTCCCG

GTGCCGGGTG CGGATATTCG ACGTCGTCGT GAAGCACTCG GTATTTCCCG

GTGCCGGGTG CGGATATTCG ACGTCGTCGT GAAGCACTCG GTATTTCCCG

GTGCCGgGtG CGgAtATtCG ACGTCGTCGT GAAGCACTCG GTATTTCCCG

GTGCCGGGTG CGGATATTCG ACGTCGTCGT GAAGCACTCG GTATTTCCCG

GTGCCGGGTG CGGATATTCG ACGTCGTCGT GAAGCACTCG GTATTTCCCG GCGTTGAGCG CGTAtATTCG ACGTCGTCGT GAAACGCTCT TCGTTGCCCA

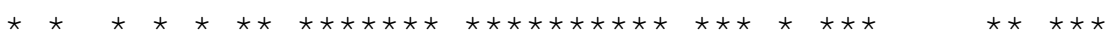

$\ldots|\ldots| \ldots|\ldots| \ldots|\ldots| \ldots|\ldots| \ldots|\ldots| \ldots \mid$

$\begin{array}{llll}60 & 70 & 80 & 90\end{array}$

TCGCTGgTCT CTTCAATGA ATTTCAgtTT TCAAAACGgC TTCTCTGgGC

TCGCTGGTCT CTTCAATGA ATTTCAGTTT TCAAAACGGC TTCTCTGGGC

TCGCTGgTCT CTTCAATGA ATtTCAGTTT TCAAAACGgC TTCTCTGGGC

TCGCTGGTCT CTTCAATGA ATTTCAGTTT TCAAAACGGC TTCTCTGGGC

TCGCTGgTCT CTTCAATGA ATtTCAgtTT tCAAAACGgC TTCTCTGgGC

TCGCTGGTCT CTTCAATGA ATTTCAGTTT TCAAAACGGC TTCTCTGGGC

TCGCTGGTCT CTTCAATGA ATTTCAGTTT TCAAAACGGC TTCTCTGGGC

TCGCTGGTCT CTTCAATGA ATTTCAgTTT TCAAAACGGC TTCTCTGGgC

TCGCTGGTCT CTTCAATGA ATtTCAgTtT TCAAAACGGC TTCTCTGGGC

TCGCTGGTCT CTTCAATGA ATTTCAGTTT TCAAAACGGC TTCTCTGGgC

TCGCTGGTCT CTTCAATGAG ATTTCAGTTT TCAAAACGGC TTCTCTGGGC GTACTGACTC GGCTTGCCGG GTTTCAGTCT TCGAAACGGC TTCTCTGGGC 

A.b_Sintanur
A.b Pertiwi
A.b-Inpari Sidenuk
A.b_Ciherang
A.b_Gondo Roso
A.b_Hibrida Prima
A.b-Pandan Wangi
A.b_India
A.b Cina
A.b Rusia
A.b-Taiwan
A.P-Iran
Clustal Co

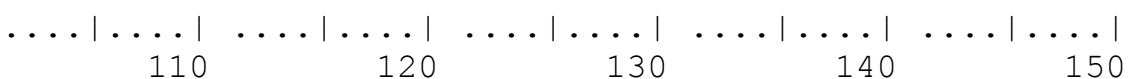

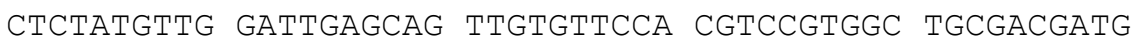
CTCTATGTTG GATtGAGCAG TTGTGTtCCA CGTCCGTGGC TGCGACGATG CTCTATGTTG GATTGAGCAG TTGTGTTCCA CGTCCGTGGC TGCGACGATG CTCTATGTTG GATTGAGCAG TTGTGTTCCA CGTCCGTGGC TGCGACGATG CTCTATGTTG GATtGAGCAG TTGTGTtCCA CGTCCGTGGC TGCGACGATG CTCtATgtTg GAtTgAgCAg tTgtgtTCCA CGTCCGTGGC TGCGACGATG

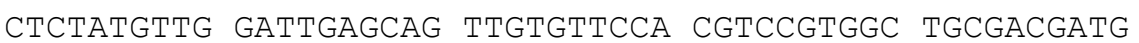
CTCTATGTTG GATTGAgCAg TTGTGTTCCA CGTCCGTGGC TGCGACGATG

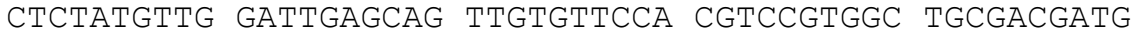
CTCtATgtTg GATTGAgCAg TTGTGTTCCA CGTCCGTGGC TGCGACGATG CTCTATGTTG GATtGAgCAg TTGTGTTCCA CGTCCGTGGC TGCGACGATG CTCtATgtTG GATtGAGCAG TTGTGTTCCA CGTCCGTGGC TGCTGAGAAG

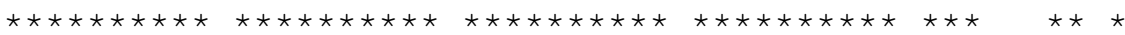
$\ldots|\ldots| \ldots|\ldots| \ldots|\ldots| \ldots|\ldots| \ldots|\ldots| \ldots|\ldots|$
160
170
180
190
200

TCCAATAgTA GCACCGCTTC GgCGgtgtTA GAgTtgAtGA CCCGGTCGgG TCCAATAGTA GCACCGCTTC GGCGGTGTTA GAGTTGATGA CCCGGTCGGG A.b Pertiwi A.b-Inpari Sidenuk A.b_Ciherang TCCAATAGTA GCACCGCTTC GgCGgtgttA GAgttgAtGA CCCGgtCGgG TCCAATAGTA GCACCGCTTC GGCGGTGTTA GAGTTGATGA CCCGGTCGGG TCCAATAGTA GCACCGCTTC GGCGGTGTTA GAGTTGATGA CCCGGTCGgG TCCAATAGTA GCACCGCTTC GGCGGTGTTA GAGTTGATGA CCCGGTCGGG TCCAATAGTA GCACCGCTTC GGCGGTGTTA GAGTTGATGA CCCGGTCGGG TCCAATAGTA GCACCGCTTC GGCGGTGTTA GAGTTGATGA CCCGGTCGGG TCCAATAGTA GCACCGCTTC GgCGgTGTTA GAgTTGATGA CCCGgTCGgG TCCAATAgTA GCACCGCTTC GgCGgtgtTA GAgTtgAtgA CCCGgtCGgG TCCAATAGTA GCACCGCTTC GGCGGTGTTA GAGTTGATGA CCCGGTCGGG TCTGACGATC GCGTCGCTTC GGCGGCGCTA GAGTTGATGA CCCGGTCGGG

A. p-Iran

clustal Co

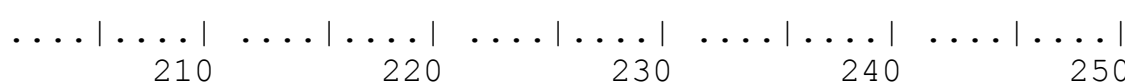

A.b_Sintanur

CACCCAGAAC CAACAACCCA TTTTCAATTC TTCAATGCCA ACTAATCGA

CACCCAGAAC CAACAACCCA TTTTCAATTC TTCAATGCCA ACTAATCGAG

A.b_Pertiwi

A.b Ciherang

A.b_Gondo Roso

A.b_Hibrida Prima

A.b_Pandan Wangi

A.b_India

A.b-Cina

A.b_Rusia

A.b_Taiwan

A.P Iran

Clustal Co

\section{A.b_Sintanur}

A.b-Pertiwi

A.b_Inpari Sidenuk

A.b_Ciherang

A.b_Gondo Roso

A.b-Hibrida Prima

A.b-Pandan Wangi

A.b_India

A.b_Cina
CCAGAA

CACCCAGAAC

CACCCAGAAC

CACCCAGAAC

CACCCAGAAC

CACCCAGAAC

CACCCAGAAC

CACCCAGAA

CACCCAGAAA

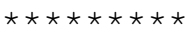

$\ldots|\ldots|$

CAACAACCCA TTTTCAATTC

CAACAACCCA TTTTCAATTC TTCAATGCCA ACTAATCGAG CAACAACCCA TTTTCAATTC TTCAATGCCA ACTAATCGAG CAACAACCCA TTTTCAATTC TTCAATGCCA ACTAATCGAG CAACAACCCA TTTTCAATTC TTCAATGCCA ACTAATCGAG CAACAACCCA TTTTCAATTC TTCAATGCCA ACTAATCGAG CAACAACCCA TTTTCAATTC TTCAATGCCA ACTAATCGAG CAACAACCCA TTTTCAATTC TTCAATGCCA ACTAATCGAG CAACAGCCCA TTTTCAATTC TTCAATGCCA ACTAATCGAG CAACAACCCA ATAACACTAC ATCAATGCGA ATAAAAgGAG

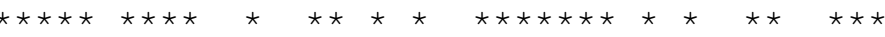
260 $\ldots \mid \ldots$ . 1 $\ldots|\ldots|$ $\ldots|\ldots| \ldots|\ldots| \ldots \mid$ CAAGTTATGT CGGTGAATCA CTTGGCTCGT GGGTCGATGA AGAACGCAGT CAAGTTATGT CGgTGAATCA CTTGgCTCGT GgGTCGATGA AgAACGCAGT CAAGTtATgt CGgtgAATCA CTTGgCtCGT GgGtCGAtgA AgAACGCAGT CAAGTTATGT CGgTGAATCA CTTGgCtCGT GgGTCGATGA AgAACGCAGT CAAGTTATGT CGgtgAATCA CTTGgCtCGT GgGtCGAtgA AgAACGCAgT CAAgtTAtgt CGgtgAAtCA CTtggCtCGt GgGtCGAtgA AgAACGCAgt CAAGTTATGT CGgtgAATCA CTTGgCtCGT GgGTCGATGA AgAACGCAGT CAAGTTATGT CGgTGAATCA CTTGgCtCGT GgGtCGATGA AgAACGCAGT 
A.b_Rusia
A.b-Taiwan
A.P_Iran
Clustal Co

A.b_Sintanur

A.b-Pertiwi

A.b_Inpari Sidenuk

A.b_Ciherang

A.b_Gondo Roso

A.b-Hibrida Prima

A.b_Pandan Wangi

A.b_India

A.b_Cina

A.b Rusia

A.b_Taiwan

A.P_Iran

Clustal co

A.b_Sintanur

A.b-Pertiwi

A.b_Inpari Sidenuk

A.b_Ciherang

A.b-Gondo Roso

A.b Hibrida Prima

A.b_Pandan Wangi

A.b_India

A.b Cina

A.b-Rusia

A.b_Taiwan

A.P_Iran

Clustal Co

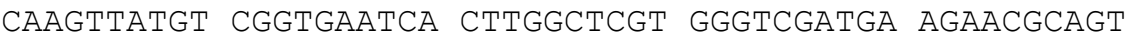
CAAgtTAtgt CGgtgAAtCA CTTGgCtCGT GgGtCGAtgA AgAACGCAgt AAAgtTAtgt CGgTgGAtCA CTTGgCtCGT GgGtCGATGA AgAACGCAGT

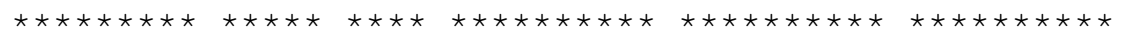

GAATTGCGTT AAtAAGCACG AATTACAGAT ATtACGAGTG CCTTGTTTTC GAATTGCGTT AAtAAGCACG AATTACAGAT ATtACGAGTG CCTTGTTTTC GAATTGCGTT AATAAGCACG AATTACAGAT ATTACGAGTG CCTTGTTTTC

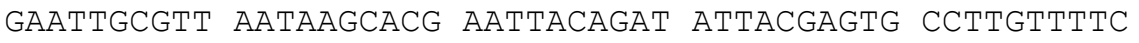
GAATtGCGTT AAtAAGCACG AAtTACAgAt AtTACGAGTG CCTTGTTtTC GAATTGCGTT AATAAGCACG AATTACAGAT ATTACGAGTG CCTTGTTTTC GAATTGCGTT AATAAGCACG AATTACAgAt ATtACGAGTG CCTTGTTTTC GAATTGCGT AATAAGCACG AATTACAGAT ATtACGAGTG CCTTGTTTTC GAATTGCGTT AATAAGCACG AATTACAGAT ATTACGAGTG CCTTGTTTTC GAATTGCGTT AATAAGCACG AATTACAGAT ATTACGAGTG CCTTGTTTTC GAATTGCGTT AATAAGCACG AATTACAGAT ATtACGAGTG CCTTGTTTTC GAATtGCGT AAtAAGCACG AAtTACAgAt AttAtgAgtg CCTTGtTtTC

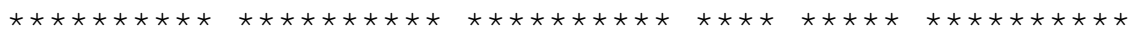
$\ldots|\ldots| \ldots|\ldots| \ldots|\ldots| \ldots|\ldots| \ldots|\ldots| \ldots|\ldots| \ldots \mid$ $\begin{array}{llll}360 & 370 & 380 & 390\end{array}$ GATTGCATAT TGCGTCGTCG GGTTCTGCCC TTCGACATAC GCAGCTCAGG GATTGCATAT TGCGTCGTCG GGTTCTGCCC TTCGACATAC GCAGCTCAGG GATTGCATAT TGCGTCGTCG GGTTCTGCCC TTCGACATAC GCAGCTCAGG GATTGCATAT TGCGTCGTCG GGTTCTGCCC TTCGACATAC GCAGCTCAGG GATTGCATAT TGCGTCGTCG GGTTCTGCCC TTCGACATAC GCAGCTCAGG GATTGCATAT TGCGTCGTCG GGTTCTGCCC TTCGACATAC GCAGCTCAGG GATTGCATAT TGCGTCGTCG GGTTCTGCCC TTCGACATAC GCAGCTCAGG GATTGCATAT TGCGTCGTCG GGTTCTGCCC TTCGACATAC GCAGCTCAGG GATTGCATAT TGCGTCGTCG GGTTCTGCCC TTCGACATAC GCAGCTCAGG GATTGCATAT TGCGTCGTCG GGTTCTGCCC TTCGACATAC GCAGCTCAGG GATTGCATAT TGCGTCGTCG GGTTCCGCCC TTCGACATAC GCAGCTCAGG GATTGCATAT TGCGCCGTCG GGCTCTGCCC TTCGGCATAC ACGGCTCAGG

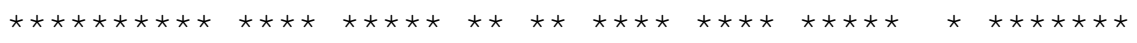

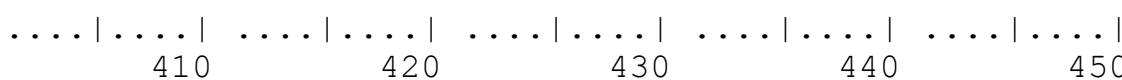
GTGTTTTCAT GGAAAgGGAA GCCAAATGCA TTGTGTAATG GTTTCGCTAT GTGTTTTCAT GGAAAGGGAA GCCAAATGCA TTGTGTAATG GTTTCGCTAT GTGTTTTCAT GGAAAGGGAA GCCAAATGCA TTGTGTAATG GTTTCGCCAT GTGTTTTCAT GGAAAGGGAA GCCAAATGCA TTGTGTAATG GTTTCGCCAT GTGTTTTCAT GGAAAGGGAA GCCAAATGCA TTGTGTAATG GTTTCGCTAT GTGTTTTCAT GGAAAGGGAA GCCAAATGCA TTGTGTAATG GTTTCGCCAT GTGTTTTCAT GGAAAGGGAA GCCAAATGCA TTGTGTAATG GTTTCGCCAT GTGTTTTCAT GGAAAgGGAA GCCAAATGCA TTGTGTAATG GTTTCGCTAT GTGTTTTCAT GGAAAgGGAA GCCAAATGCA TTGTGTAATG GTTTCGCCAT GTGTTTTCAT GGAAAgGGAA GCCAAATGCA TTGTGTAATG GTTTCGCCAT GTGTTTTCAT GGAAAGGGAA GCCAAATGCA TTGTGTAATG GTTTCGCTAT GTGTTTTAAC GAAAACGGAA ACCAACGATT CAGATTAACG GTTCCGATTT

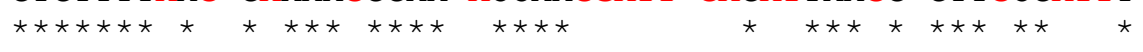

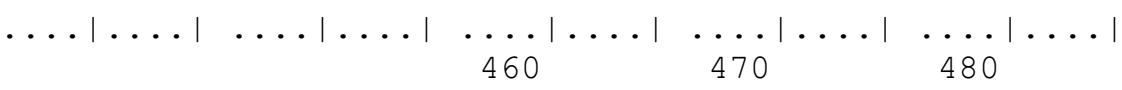

490

500

A.b_Sintanur

A.b-Pertiwi

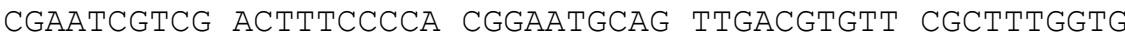

CGAATCGTCG ACTTTCCCCA CGgAATGCAG TTGACGTGTT CGCTTTGgTG

A.b_Inpari Sidenuk CGAATCGTCG ACTTTCCCCA CGGAATGCAG TTGACGTGTT CGCTTTGGTG 

A.b_Ciherang
A.b_Gondo Roso
A.b-Hibrida Prima
A.b_Pandan Wangi
A.b-India
A.b- Cina
A.b_Rusia
A.b_Taiwan
A.P_Iran
Clustal Co

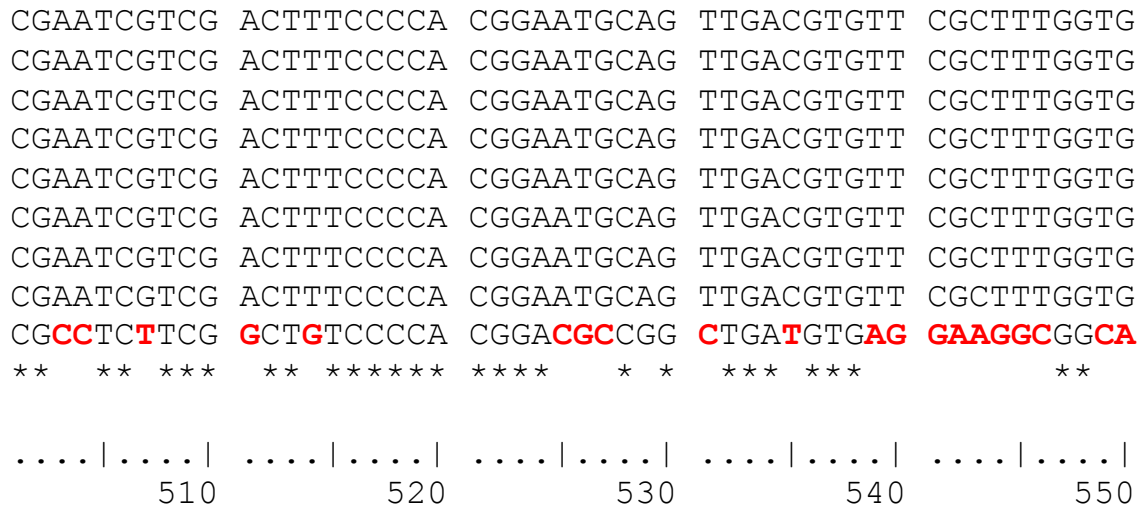

$\begin{array}{lc}\text { A.b_Sintanur } & \text { ATGTC } \\ \text { A.b_Pertiwi } & \text { ATGTC } \\ \text { A.b_Inpari Sidenuk } & \text { ATGTC } \\ \text { A.b_Ciherang } & \text { ATGTC } \\ \text { A.b_Gondo Roso } & \text { ATGTC } \\ \text { A.b_Hibrida Prima } & \text { ATGTC } \\ \text { A.b_Pandan Wangi } & \text { ATGTC } \\ \text { A.b_India } & \text { ATGTC } \\ \text { A.b_Cina } & \text { ATGTC } \\ \text { A.b_Rusia } & \text { ATGTC } \\ \text { A.b_Taiwan } & \text { ATGTC } \\ \text { A.P_Iran } & \text { GTTCC } \\ \text { Clustal Co } & \star \star\end{array}$

Gambar 3. Hasil analisis penyejajaran runutan nukleotida daerah ITS rDNA menggunakan program ClustalW [tanda * menunjukkan nukleotida yang identik]

Hasil analisis tingkat kesamaan perunutan nukleotida menunjukkan bahwa runutan ITS rDNA empat isolat $A$. besseyi asal varietas Indonesia yakni Inpari Sidenuk, Ciherang, Hibrida Prima, dan Pandan Wangi memiliki homolog $100 \%$ dengan isolat yang berasal dari negara Cina dan Rusia. Sedangkan isolat asal India memiliki homologi 99.8\% dan isolat asal Taiwan memiliki homologi $99.4 \%$ terhadap keempat isolat tersebut. Varietas Gondo Roso, Pertiwi, dan Sintanur memiliki homologi $100 \%$ dengan isolat yang berasal dari India. Sedangkan isolat asal Cina dan Rusia memiliki homologi $99.8 \%$ dan Taiwan $99.6 \%$ (Tabel 1). Menurut Khan et al. (2012), nilai tingkat kesamaan (homologi) lebih besar dari $90 \%$ pada perunutan nukleotida antara satu nematoda dengan nematoda lainnya, maka dapat dikatakan merupakan spesies yang sama dan tidak ada perbedaan genetik walaupun terdapat pada komoditas yang berbeda.

Menurut Elford \& Stansfield (2007), faktor-faktor yang mempengaruhi tingkat keragaman spesies dalam suatu wilayah yakni jumlah individu, penyebaran wilayah geografis, dan sistem genetikanya. Berdasarkan hasil analisis penyejajaran menunjukkan kesamaan runutan nukleotida yang tinggi dari tujuh isolat A.besseyi asal Indonesia memiliki tingkat kesamaan (homologi) di atas $90 \%$. Tingkat kesamaan (homologi) berdasarkan runutan nukleotida yang dimiliki isolat Inpari Sidenuk, Ciherang, Hibrida Prima, dan 
Pandan Wangi dengan negara Cina dan Rusia mencapai $100 \%$ (identik). Isolat Sintanur, Pertiwi, dan Gondo Roso memiliki homologi $100 \%$ berdasarkan runutan nukleotida dengan isolat dari India (Tabel 1). Persamaan morfologi dan genetika dari suatu populasi dapat memiliki tingkat kedekatan hubungan kekerabatan yang tinggi yang dipengaruhi oleh keadaan lingkungan (Sofro, 1994).

Tabel 1. Tingkat kesamaan (homologi) runutan nukleotida ITS rDNA A. besseyi isolat asal tujuh varietas Indonesia dibandingkan dengan GenBank menggunakan program Bioedit v.7.2.6

\begin{tabular}{|c|c|c|c|c|c|c|c|c|c|c|c|c|c|}
\hline \multirow[b]{2}{*}{ No. Aksesi } & \multirow[b]{2}{*}{ Asal Isolat } & \multicolumn{12}{|c|}{ Homologi (\%) } \\
\hline & & $\underset{\text { 芯 }}{\stackrel{\Xi}{\Xi}}$ & : & 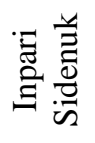 & 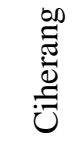 & 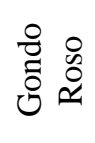 & 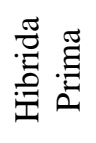 & 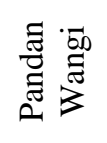 & 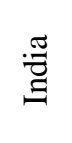 & $\stackrel{\Xi}{\Xi}$ & $\frac{\pi}{\mathscr{a}}$ & 胥 & 苂 \\
\hline- & $\begin{array}{l}\text { A. besseyi } \\
\text { Sintanur } \\
\text { Indonesia }\end{array}$ & - & & & & & & & & & & & \\
\hline- & $\begin{array}{l}\text { A. besseyi } \\
\text { Pertiwi } \\
\text { Indonesia }\end{array}$ & 100 & - & & & & & & & & & & \\
\hline- & $\begin{array}{l}\text { A. besseyi } \\
\text { Inpari } \\
\text { Sidenuk } \\
\text { Indonesia }\end{array}$ & 99.8 & 99.8 & - & & & & & & & & & \\
\hline- & $\begin{array}{l}\text { A. besseyi } \\
\text { Ciherang } \\
\text { Indonesia }\end{array}$ & 99.8 & 99.8 & 100 & - & & & & & & & & \\
\hline- & $\begin{array}{l}\text { A. besseyi } \\
\text { Gondo } \\
\text { Roso } \\
\text { Indonesia }\end{array}$ & 100 & 100 & 99.8 & 99.8 & - & & & & & & & \\
\hline- & $\begin{array}{l}\text { A. besseyi } \\
\text { Hibrida } \\
\text { Prima } \\
\text { Indonesia }\end{array}$ & 99.8 & 99.8 & 100 & 100 & 99.8 & - & & & & & & \\
\hline- & $\begin{array}{l}\text { A. besseyi } \\
\text { Pandan } \\
\text { Wangi } \\
\text { Indonesia }\end{array}$ & 99.8 & 99.8 & 100 & 100 & 99.8 & 100 & - & & & & & \\
\hline JF932290.1 & $\begin{array}{l}\text { A. besseyi } \\
\text { India }\end{array}$ & 100 & 100 & 99.8 & 99.8 & 100 & 99.8 & 99.8 & - & & & & \\
\hline KJ009342.1 & $\begin{array}{l}\text { A. besseyi } \\
\text { Cina }\end{array}$ & 99.8 & 99.8 & 100 & 100 & 99.8 & 100 & 100 & $\begin{array}{c}99 . \\
8\end{array}$ & - & & & \\
\hline EU186069.1 & $\begin{array}{l}\text { A. besseyi } \\
\text { Rusia }\end{array}$ & 99.8 & 99.8 & 100 & 100 & 99.8 & 100 & 100 & $\begin{array}{c}99 . \\
8\end{array}$ & 100 & - & & \\
\hline MF669503.1 & $\begin{array}{l}\text { A. besseyi } \\
\text { Taiwan } \\
\text { A. }\end{array}$ & 99.6 & 99.6 & 99.4 & 99.4 & 99.6 & 99.4 & 99.4 & $\begin{array}{c}99 . \\
6\end{array}$ & $\begin{array}{c}99 . \\
4\end{array}$ & 99.4 & - & \\
\hline MF991962.1 & $\begin{array}{l}\text { primadentu } \\
s \\
\text { Iran }\end{array}$ & 74.5 & 74.5 & 74.4 & 74.4 & 74.5 & 74.4 & 74.4 & $\begin{array}{c}74 . \\
5\end{array}$ & $\begin{array}{c}74 . \\
4\end{array}$ & 74.4 & 74.2 & - \\
\hline
\end{tabular}




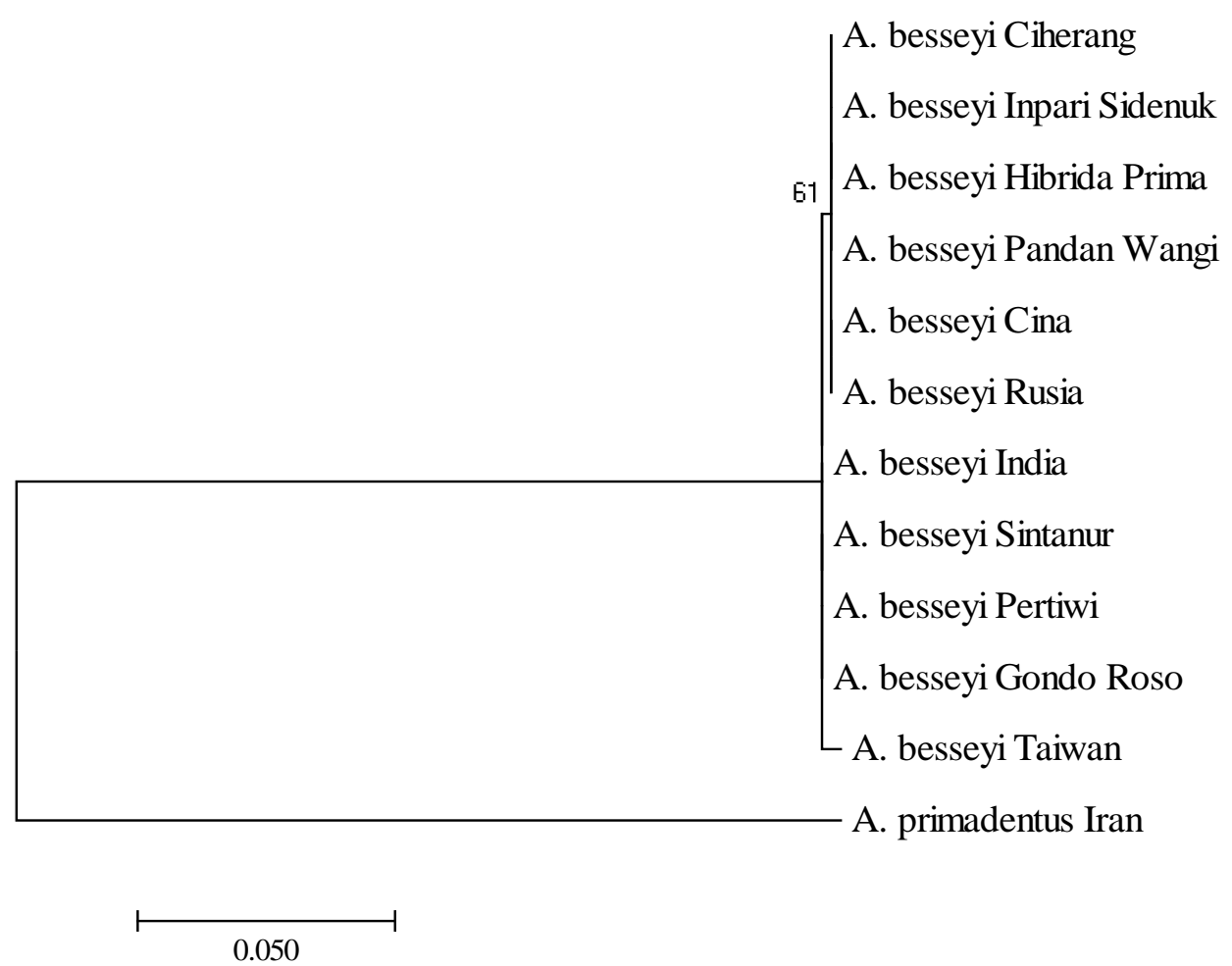

Gambar 4. Filogenetika isolat $A$. besseyi beberapa negara berdasarkan perunutan nukleotida ITS rDNA menggunakan program MEGA v.7.0 dengan metode Maximum Likelihood dengan boostrap 1000x

\section{Filogenetika Aphelenchoides besseyi}

Analisis filogenetika pada kladogram menunjukkan bahwa hubungan kekerabatan setiap isolat terbagi menjadi dua kelompok (Gambar 4). Kelompok pertama terdiri dari isolat asal Ciherang, Inpari Sidenuk, Hibrida Prima, Pandan Wangi, Cina, dan Rusia. Kelompok kedua terdiri dari isolat asal India, Sintanur, Pertiwi, dan Gondo Roso, serta isolat asal Iran sebagai outgroup. Pembentukan phylogenetic tree sangat memerlukan outgroup yang merupakan isolat yang memiliki perbedaan yang nyata dengan runutan lainnya, namun masih memiliki kedekatan. Outgroup yang terlalu jauh dapat menyebabkan terjadinya kesalahan dalam pembuatan Phylogenetic tree (Dharmayanti, 2011).

Analisis filogenetik merupakan proses pengolahan data sekuen DNA atau protein sehingga diperoleh suatu hasil yang menggambarkan hubungan kekerabatan evolusi suatu kelompok organisme (Hidayat \& Pancoro, 2008). Proses analisis filogenetik nematoda digunakan hasil perunutan nukleotida untuk mengetahui asal usul nematoda yang terbawa benih. Isolat $A$. bessseyi asal Indonesia Inpari Sidenuk, Ciherang, Pandan Wangi, dan Hibrida Prima berada pada kelompok yang sama yakni kelompok monofiletik dengan isolat asal Rusia dan Cina, sehingga dapat dikatakan memiliki asal usul yang sama begitu juga isolat Indonesia Sintanur, Pertiwi, dan Gondo Roso berada pada kelompok monofiletik dengan isolat asal India.

\section{KESIMPULAN}

ITS rDNA Aphelenchoides besseyi asal tujuh varietas padi Indonesia berhasil diamplifikasi menggunakan primer spesifik. Ukuran fragmen ITS rDNA diamplifikasi sekitar $\pm 750 \mathrm{pb}$. Hasil perunutan nukleotida yang diperoleh berukuran 555 nukleotida. Berdasarkan hasil analisis penyejajaran diketahui bahwa isolat ITS rDNA A. besseyi asal varietas Inpari Sidenuk, Ciherang, Hibrida Prima, dan Pandan Wangi memiliki homologi nukleotida $100 \%$ dengan isolat asal Cina dan Rusia, sedangkan isolat asal Sintanur, Pertiwi, dan Gondo Roso memiliki homologi 100\% dengan isolat asal India. Berdasarkan analisis filogenetika terdapat outgroup dari isolat ITS rDNA A. primadentus asal Iran yang memiliki homologi nukleotida sebesar $74.5 \%$. Hal ini menunjukkan bahwa isolat $A$. besseyi asal Indonesia memiliki kesamaan identik dan berkerabat sangat dekat dengan isolat asal Cina, Rusia, dan India.

\section{DAFTAR PUSTAKA}

Dharmayanti, N.L.P.I. 2011. Filogenetika Molekuler: Metode Taksonomi Organisme. Wartazoa. 21(30): 110 .

Doyle, J.J., J.L. Doyle. 1990. A Rapid Total DNA Preparation Procedure for Fresh Plant Tissue. Focus. 12:13-15. 
Elford, S.L., W.D. Stainsfield. 2007. Genetika. Damaringtyas, penerjemah. Jakarta. Erlangga.

European and Mediterranean Plant Protection Organization. 2005. Pest Rial Analysis Aphelenchoides besseyi Christie on Rice (Oryza sativa L.). Italy. Rise Researh Centre.

Gomes, E.A., M.C. Kasaya, E.G. deBarros, A.C. Borgs, E.F. Araujo. 2002. Polymorphism in The Internal Transcribed Spacer (ITS) of The Ribosomal DNA of 26 Isolates of Ectomycorrhizal Fungi. Genet Mol Biol. 25(4):477-483.

Hall, T.A. 1999. Bioedit: a User-Friendly Biological Sequence Alignment Editor and Analysisprogram For Windows 95/98/NT. Nucleic Acids Symp. Ser. 41:9598.

Hidayat, T., A. Pancoro. 2008. Kajian Filogenetika Molekuler dan Peranannya dalam Menyediakan Informasi Dasar untuk Meningkatkan Kualitas Sumber Genetik Anggrek. J ArgoBiogen. 4(1):35-40.

Kementerian Pertanian Republik Indonesia. 2015. Peraturan Menteri Pertanian Nomor 51/Permentan/KR.010/9/2015. Jakarta. Kementan.

Kementerian Pertanian Republik Indonesia. 2018. Peraturan Menteri Pertanian Nomor 31/Permentan/KR.010/7/2018. Jakarta. Kementan.
Khan, M.R., Z.A. Handoo, U Rao, S.B. Rao, J.S. Prasad. 2012. Observations on The Foliar Nematode, Aphelenchoides besseyi, Infecting Tuberose and Rice in India. J Nematol. 44(4):391-398.

Kurniawati, F., Supramana. 2016. Tingkat Infestasi Aphelenchoides besseyi pada Benih Padi di Bogor. Jurnal Fitopatol Indones. 12 (1): 34-37. Doi 10.14692/jfi.12.1.34.

National Center for Biotechnology Information. 2014. Basic Local Alignment Search Tool. [Internet]. [Diakses 2015 Mei 20]. Tersedia pada: http://www.nbci.nlm.nih.gov/BLAST.

O'Brien, H.E., J.L. Parrent, J.A. Jackson, J.M. Moncalvo, \& R. Vilgalys. 2005. Fungal Communities' Analysis by Large-Scale Sequencing of Environmental Samples. Environ Microbiol 71: 5544-5550.

Remeeus, P.M., N. Pelazza. 2014. Detection of Aphelenchoides besseyi on Oryza sativa. Di dalam: B. Kaufman, R. El-Khadem, P. Muschick, \& J. Taylor, editor. International Rules of Seed Testin. Bassersdorf. ISTA.

Sofro, A.S.M. 1994. Keanekaragaman Genetik. Yogyakarta. Andi Offset.

Vrain, T.C., D.G. McNamara. 1994. Potential for Identification of Quarantine Nematodes by PCR. EPPO Bulletin. 24:453-458. 